\title{
Entertaining or Functional: An Analysis of Visuals in Chinese and Western Household Appliance Manuals
}

\author{
Qian Li \\ University of Twente \\ q.li@utwente.com
}

\author{
Joyce Karreman \\ University of Twente \\ j.karreman@utwente.nl
}

\author{
Menno D.T. de Jong \\ University of Twente \\ m.d.t.dejong@utwente.nl
}

\begin{abstract}
In today's global world, understanding local user preferences becomes an increasingly essential skill, especially for technical communicators who design products for people in other cultures. This study attempts to analyze and compare visuals in Chinese and Western manuals because visuals play an essential role in manuals. Based on a systematically designed coding scheme, we analyzed 50 Western and 50 Chinese household product manuals (1895 pages in total) designed in their own cultures and published after 2007. Results show many differences between Chinese and Western manuals with regard to visuals. All differences seem to point in the same direction; Chinese visuals appear to have an entertaining function while Western visuals are not meant to entertain the readers but have an informative or instructive function. This study aims to enhance the mutual understanding of information designers in cross-cultural manual design.
\end{abstract}

Index Terms - Chinese culture, cross-cultural communication, user manual, visuals, western culture

\section{INTRODUCTION}

Pictures are always of importance in manuals. They have many benefits; as the saying goes "a picture is worth a thousand words". Visuals require little knowledge of the product or language; encourage people to read the accompanying text; call for less cognitive efforts than text, and they can be processed in a distracting environment [1]. However, new challenges due to the globalization have emerged. Cultural differences should be taken into consideration in visual designs [1]. Pictures are not universal but culture-specific [2]. People from different cultural backgrounds appreciate and prefer different visuals [3]-[7]. As a result of repeated exposure over time passes, people in different cultures have different expectations of what a particular visual should look like [5], [8]. Moreover, the usability of manuals may be influenced by expectations and by the appreciation of visuals dependent on culture [4], [9].

Regardless of the advantages, localization of manuals is mostly done superficially, mostly on the textual part, without regard to cultural factors [10], [11]. In terms of research, the rhetoric of visuals is mainly studied in the Western world [4], [12]. So, the design and use of visuals in manuals from different cultures need attention because of the increasing importance of visuals and the lack of knowledge on the necessity to localize them.

Chinese and Western manuals are studied in this paper. Because these two cultures are the most distant and the least influenced by each other [13]. An important difference is that Western cultures are considered to be "low-context cultures" where most information is explicit, while the Chinese culture is a "high-context culture" where most information is conveyed in the context or shared by people, with few explicit messages [14].

There is already a considerable number of studies published on differences Chinese and Western documents and many studies have been conducted to compare the visual differences between China and Western countries within the field of technical communication. Although these studies are valuable, most of these studies have some disadvantages. First, most studies are rather small, including a small number of manuals that are studied. In addition, the methods used were mostly informal, and the comparisons were not completely systematically carried out. Last but not least, some studies were published decades ago, but culture is dynamic and keeps changing. Design related to cultures needs to be continuously reassessed [15].

Therefore, this study compares the use of visuals by analyzing a large number of Chinese and Western manuals. The research question is how Chinese and Western manuals differ from each other with respect to their visual design. 


\section{LITERATURE REVIEW}

This section reviews key earlier findings in five aspects: the total number of visuals, visual types, the relationship between visuals and texts, visual-text position, and color.

\section{Total number of visuals}

Recent researches have suggested that Chinese manuals use more pictures. For example, it is shown that more pictures appear in Chinese automobile manuals than in German ones [16], [17]. Similarly, Kong [18] suggests that Chinese newspapers tend to employ more photos compared to their English counterparts. Besides, it is identified that there are more pictures on Taiwan government websites than on government websites in the UK [19]. It has also been shown that in other eastern cultures, such as in Japan, pictures are more dominant in consumer product instructions than in English instructions, which include more textual information [20].

There are several possible explanations for these results. Some researchers attribute the results to different preferences; Chinese users like pictorial information and German prefer texts [21]. China has a long history of involving numerous detail drawings to help users finish their tasks [22]. Some researchers state that Chinese people have a better understanding of graphics than Germans because of their visual comprehension ability caused by Chinese pictographic scripts [16], [17]. Others consider Chinese users are easier to be affected by visuals compared to Western users, such as Swiss people, and thus it is suggested to add more pictures in Chinese interfaces [11].

\section{Visual types}

There are many types of pictures in manuals, such as line drawings, photographs, icons, and infographics [23]. Visuals in manuals reflect the social and cultural beliefs, so it might be that people from different cultural backgrounds appreciate different types of visuals [3].

Firstly, one of the most impressive differences regarding the use of visuals between high context and low context cultures is the use of cartoons, personifications of products or cute style pictures [19], [20], [24], [25]. Cartoons seem to appeal to Chinese people, especially from the age of 15 to 25 who prefer cuteness [4]. Building a good relationship with the reader is highly emphasized in Chinese culture and these cartoons can "make difficult tasks seem like fun" and "would create a friendly appearance" [25, p. 169]. S. Li [26] agrees with the importance of relationship building in manuals. She puts forward that the traditional Chinese user manuals are too distant from the audience and should be more userfriendly. In this case, some cartoon-like pictures can be helpful in Chinese manuals.
Additionally, visuals for experts that do not seem to be usable or understandable for the general public are used more often in Chinese manuals. Electric circuit diagrams, which are expected to be targeted to experts, appear in many Chinese manuals and do not appear often in American ones [2], [27].

Finally, pictures to depict action steps are suggested to be more detailed in Chinese manuals than in Chinese ones [2]. Besides, An overview of the product, instead of a detailed depiction of operation is in Chinese operational visuals [26].

\section{. The relationship between visuals and texts}

It is a challenge for information developers to understand how text and visuals work together to make the documents more effective and more usable for the reader [3].

In Chinese manuals, the connection between visuals and the accompanying text is less clear through positioning or labeling than in Western manuals [22], [27]-[29]. This probably stems from the fact that users are expected to comprehend the accompanying text with their background knowledge in a high context culture with many common senses shared while the relationship should be specified in a low context culture [29], [27].

Yiqin Wang and Wang [17, p. 44] classify the relationship between text and visuals into two types: elaborative/complementary: "text and graphics complement each other" and redundant: "a detailed text description is provided when the graphics alone are sufficiently illustrative". Speaking of differences, research has shown the visual-text relationship is elaborative in Chinese manuals while redundant in German manuals [16].

Schriver [30] distinguished five types of picture text relationships in instruction manuals, redundant, complementary, supplementary, juxta positional, and stage-setting. Except for the five relationships, Carney and Levin [31] propose the decorational relationship, where pictures are used to decorate the page or to motivate learners. They assume decorational pictures make texts more attractive to readers, however, they have no real instructional purpose and should be limited. What's more, it is supposed that decorational pictures may confuse readers [32]. Nevertheless, this decorational relationship is especially more visible in high context cultures, where aesthetic proposes are central, compared to technical or explanatory purposes in low context cultures [24]. Some authors [33] believe that Japanese emphasize aesthetics a lot and that it is important for them to give readers a good impression. So, visuals don't necessarily need to be related to the text. For Americans, on the other hand, visuals should be clear and comprehensible for the readers to follow. 


\section{Visual and text position}

It has commonly been assumed that position preference is culturally different. It is preferable to put tables on the right in America while left in Asian cultures [34]. Besides, pictures are often arranged vertically to texts in Chinese and horizontally in German manuals [16], [17].

\section{Color}

The color and color categorization is assumed to be perceived in different ways by Asian and Western people [8], [35]. According to recent reports, Chinese users favor a colorful interface and Westerners prefer a monotonously colored one [19], [35], [36]. There is some evidence to suggest that things are stated clearly in the low context culture, and a consistent layout and color scheme is easier to interpret for people in that culture [37]. At the same time, more things are left unsaid in high context cultures, so diverse layout and color schemes are preferred [37]. However, it is left unsaid or unexplored how this kind of difference is reflected in the design of user manuals in Western and Chinese cultures.

\section{Conclusion}

All studies referred to suggest differences between the use of visuals in Chinese and Western manuals. However, a large size, systematic and comprehensive study is needed to analyze different design strategies that are used by information designers from China and Western countries.

\section{METHODOLOGY}

The content analysis included 50 Western and 50 Chinese household product manuals designed in their own cultures and published after 2007. The manuals were analyzed according to a coding scheme, using ATLAS.ti ${ }^{\circledR}$ software. The coding scheme was designed based on the findings of previous studies and on the analysis of 10 preselected manuals. A second coder was assigned 10 (5 Chinese and 5 English) randomly selected manuals and coded those manuals to ensure reliability. The Cohen's Kappa value is 0.90 , with a significance of $\mathrm{p}<0.0005$, which shows very high agreement between the first and the second coder. Finally, data were exported to SPSS and independent-samples t-tests and chi-square test were used to test if there were statistically significant differences between Chinese and Western manuals.

\section{Manual collection}

The choice to include only household appliance manuals in the content analysis was based on the following reasons. Firstly, household appliances are targeted at the general public and nowadays people use many household appliances [38]. So, this type of manual represents the popular design style in society. Secondly, previous studies suggested cultural differences in household appliance manuals [20], [25], [27]-[29], [38][40]. Finally, the industries of household appliances are developing very fast in both Chinese and Western countries, which enhances comparability.

It's impossible and impractical to include all products, so products were chosen which meet the following requirements. To begin with, products should not too simple and should have sufficient functions. In addition, products should be widely used in both cultures. Those products were excluded which are popular in one culture but seldom used in the other culture, such as electric massage devices or soya milk producers which are not common in Western cultures. Finally, the product categories chosen should have different functionalities, which can help to cover numerous types of manuals.

Based on the principles above, 10 product categories are made, which include refrigerators, washing machines, water heaters, vacuum cleaners, air purifiers, humidifiers, food processors, televisions, space heaters and wireless speakers. For each category, 5 brands were randomly selected (using a few criteria) from the websites that rank household brands by quality, popularity and other official statistics in both two cultures. Brands refer to local original brands. For example, Siemens is a brand originated from Germany, so it is counted as a Western brand instead of a Chinese one, although its products are also sold in China. Besides this, the selected brands are all commonly known in their own culture.

After selecting the brands, one manual for each brand was chosen. Selected manuals were randomly obtained through official channels such as websites and offline stores.

Fifty Chinese manuals and fifty Western manuals were included in this study. All manuals were published from 2007 to 2016. All Western manuals were downloaded from the official websites $(\mathrm{N}=50)$, while only 29 Chinese manuals were from their official websites. The other manuals were fetched from other manual websites (11), the printed version in stores (3), Wechat (3), Weibo (1), service line (1), JingDong (1) and emails (1). The selected Chinese manuals $(\mathrm{M}=14.16, \mathrm{SD}=7.023)$ counted significantly less pages than the Western manuals (M $=23.74, \mathrm{SD}=21.76)(\mathrm{F}=10.273, \mathrm{p}=.00<0.05)$.

\section{- Coding scheme}

To analyze selected 100 manuals, a coding scheme was needed to categorize data. The coding scheme used in the study was designed both top-down and the bottom-up.

Codes were guided by the five categories summarized from the previous findings. The coding process started by randomly selecting ten manuals (five Chinese and five Western) that were used to conduct open coding. All manuals were scanned to have a general impression of possible differences. Next, all texts were read word by word and marked when possible differences appeared. 
After finishing coding 10 manuals, these marked differences were examined to be classified into several categories. Some codes were added under the five categories, such as a user-interface icon in the visual type and a new one emerged: human appearance, that show whether human images or gender are depicted in pictures.

On the basis of this classification, 100 manuals were analyzed respectively. The total pages were 1895 .

\section{Data analysis}

Collected data were exported from ATLAS.ti and analyzed in SPSS. Because the Chinese manuals counted less in pages than the Western manuals, the influence of the number of pages should be eliminated. At first, oneway between-groups analysis of covariance was conducted to compare the differences of Chinese and Western manuals, but most codes violated the assumption of homogeneity of regression of slopes. So, codes covariant with pages were divided by pages. The total number of visual code was divided by the total number of pages, and all the other codes expect position type, manual color, and front page color were divided by the total number of visuals.

Then non-parametric codes were analyzed by the independent-samples t-test, and parametric codes by the chi-squared test.

Apart from the analysis of a single code, we also wanted to know the relationship between two codes by analyzing the occurrence data from ATLAS.ti. For example, besides comparing the total number of visuals, this study also takes into account the number of visuals in declarative information to describe product information and operational information to describe steps. Therefore, we compared the concurrence of two types of codes: visual and accompanying text types (declarative/operational information).

\section{RESULTS}

The section below describes results of visual comparisons. Table 1 illustrates related statistics. Note that the relation between two codes is not shown in the table but discussed in the text.

TABLE 1. RESULTS OF THE VISUAL COMPARISON.

\begin{tabular}{|l|l|l|l|}
\hline \multirow{2}{*}{ Code } & \multicolumn{2}{|l|}{ Mean (SD) } & \multirow{2}{*}{ Sig } \\
\cline { 2 - 4 } & Chinese & Western & \\
\hline Visual numbers & $2.44(1.47)$ & $2.05(1.80)$ & 0.23 \\
\hline Total visual & $0.53(0.26)$ & $0.40(0.30)$ & 0.02 \\
\hline Visual in declarative & $0.35(0.23)$ & $0.45(0.30)$ & 0.09 \\
\hline Visual in operational & \multicolumn{3}{|l}{} \\
\hline Visual types & $0.12(0.23)$ & $0.12(0.27)$ & 0.98 \\
\hline Image & $0.34(0.11)$ & $0.01(0.05)$ & 0.14 \\
\hline Screen capture & $0.10(0.20)$ & $0.00(0.00)$ & 0.00 \\
\hline $\begin{array}{l}\text { Cartoon with } \\
\text { personification }\end{array}$ & &
\end{tabular}

\begin{tabular}{|c|c|c|c|}
\hline \multirow{2}{*}{ Code } & \multicolumn{2}{|l|}{ Mean (SD) } & \multirow{2}{*}{ Sig } \\
\hline & Chinese & Western & \\
\hline Cartoon & $0.22(0.27)$ & $0.06(0.17)$ & 0.00 \\
\hline Technical line & $0.46(0.31)$ & $0.65(0.34)$ & 0.00 \\
\hline Detail blow-up & $0.01(0.02)$ & $0.03(0.05)$ & 0.00 \\
\hline Circuit diagram & $0.04(0.09)$ & $0.01(0.03)$ & 0.02 \\
\hline UI icon & $0.11(0.18)$ & $0.15(0.23)$ & 0.39 \\
\hline Other types & $0.02(0.04)$ & $0.00(0.01)$ & 0.01 \\
\hline \multicolumn{4}{|c|}{ Visual-text relationship } \\
\hline Redundant & $0.58(0.31)$ & $0.58(0.29)$ & 0.83 \\
\hline Not redundant & $0.28(0.26)$ & $0.26(0.28)$ & 0.71 \\
\hline Decorational & $0.03(0.10)$ & $0.01(0.02)$ & 0.16 \\
\hline Position hard to find & $0.01(0.03)$ & $0.01(0.02)$ & 0.82 \\
\hline \multicolumn{4}{|l|}{ Visual-text position } \\
\hline Left & $0.13(0.25)$ & $0.15(0.23)$ & 0.66 \\
\hline Right & $0.20(0.23)$ & $0.11(0.18)$ & 0.03 \\
\hline Above & $0.10(0.14)$ & $0.16(0.19)$ & 0.08 \\
\hline Below & $0.48(0.32)$ & $0.45(0.30)$ & 0.67 \\
\hline In & $0.08(0.15)$ & $0.12(0.21)$ & 0.37 \\
\hline Position type $^{1}$ & $\begin{array}{l}18 \%, 32 \% \\
26 \%, 24 \%\end{array}$ & $\begin{array}{l}16 \%, 36 \% \\
38 \%, 10 \%\end{array}$ & 0.23 \\
\hline \multicolumn{4}{|l|}{ Color } \\
\hline Manual color ${ }^{2}$ & $32 \%$ & $16 \%$ & 0.10 \\
\hline Visual color $^{3}$ & $0.12(0.22)$ & $0.14(0.25)$ & 0.62 \\
\hline Front page color & $58 \%$ & $34 \%$ & 0.03 \\
\hline \multicolumn{4}{|l|}{ Human appearance } \\
\hline Human & $0.02(0.04)$ & $0.00(0.01)$ & 0.00 \\
\hline Gender & $0.02(0.04)$ & $0.00(0.01)$ & 0.01 \\
\hline
\end{tabular}

Note: 1 . Values of position type are 1 (only one position type of visual to text in one manual), 2, 3, and 4.

2,3 . Results show the percentage of colorful manuals and front pages.

\section{Total number of visuals}

In contrast to earlier findings, however, no evidence of a higher number of visuals in Chinese manuals has been found. Nonetheless, a statistical trend toward significance shows that somewhat more pictures are used in the operational information in Western manuals than in Chinese manuals. On the contrary, in Chinese manuals, there are more visuals appear in declarative texts that specify all information except actions, such as safety information, concept definition, and product specification.

\section{- Visual types}

The majority of visual types are utilized in a different manner between Chinese and Western manuals.

Chinese manuals are more likely to include four types of pictures: a cartoon with personification (the picture of non-living thing represented as if it were a living being, as shown in Figure 1), cartoons that draw abstract and simple pictures of things that don't have the same size or dimension as the real one, circuit diagrams that represent an electrical circuit with the components and interconnections of the circuit (as shown in Figure 1), and other type of visuals such as QR codes and flowcharts. In 
particular, cartoons with personification are shown more often in declarative texts. At the same time, circuit diagrams rarely accompany actions, so there is only the difference related to declarative information. Last, other types of visuals are used more often only in operational texts.
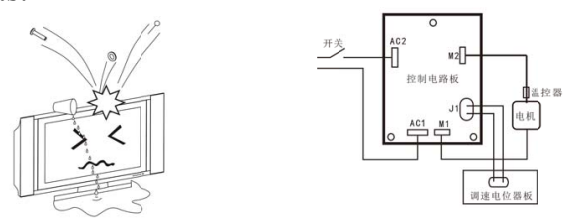

FIGURE 1. EXAMPLE OF CARTOON WITH PERSONIFICATION, AND CIRCUIT DIAGRAMS IN CHINESE MANUALS.

On the other hand, two visuals types tend to be used more often in the Western manual: detail-blow up visuals that demonstrate details with enlarged scale and technical line drawings that depict the same size and dimension proportion as the real object (as shown in Figure 2). Specifically, detail-blow up visuals are more often used in declarative and operational information while the technical line drawings are more often used in operational texts.
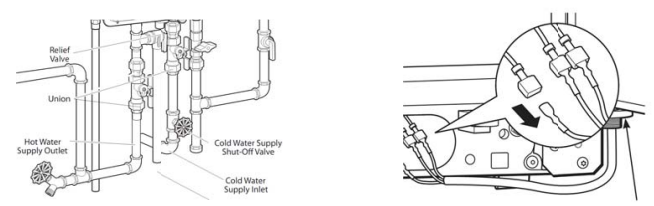

FIGURE 2. EXAMPLE OF TECHNICAL LINE DRAWINGS AND DETAIL-BLOW UPS IN WESTERN MANUALS.

There are also some similarities between Chinese and Western manuals: images (real pictures taken by the camera or the scanner, exactly how things look), screen captures (digital image created by certain operating system or software), and UI icons (icons in the user interface of products) are used as frequently in Chinese manuals as in Western manuals.

\section{The relationship between visuals and texts}

The result of the relationship between visuals and texts is beyond expectation. It is not difficult to find the corresponding texts to visuals in both Chinese and Western manuals. It seems that both take advantage of clues such as position and labels to help users figure out the relation.

Furthermore, no significant difference was found regarding more specific relations: redundant (a picture that visualizes something that has been mentioned in the texts.), not redundant (a picture that gives out additional information.), or decorational (a picture that decorates the page without real instructional purposes [32]).

\section{Visual and text position}

What stands out in table 1 is the frequency of positioning the visual to the right of the text in Chinese manuals, different from the preferred left position [34]. This preference is especially strong when visuals are related to declarative information.

What worth noticing is that table 1 indicates a tendency that visuals in Western manuals are more often put above the text, especially in operational texts. So, the assumed horizontal arrangement in Chinese manuals and the vertical arrangement in Western manuals [16], [17] seems to be not completely true.

\section{. Color}

There are three codes related to colors discussed in this study. The first one is the color of the picture. The second one is the color of the front page. The last one is the color of the whole manual, excluding the front page and visuals.

Results reveal that $58 \%$ of Chinese front pages are colorful while only $34 \%$ of Western front pages. It is economically beneficial to design a colorful front page instead of a whole manual. What's more, the front page leaves the first impression to users, so a colorful cover may attract user's attention.

Meanwhile, the results indicate that manuals in both cultures apply color to a certain percentage of visuals, and they show no differences with regard to the number of colorful manuals or visuals. Still, more than half of manuals do not use any color, and one of the possible reasons could be the high cost of color printing.

\section{. Human appearance}

The way people are represented seems to be culturally dependent, according to the results. Human images appear more often in Chinese visuals, and even gender roles are more obvious than in Western manuals (as shown in Figure 3). For example, males are shown to move heavy appliances and females to do cleanings. In Western manuals, gender is always blurred. More specific, these differences exist only in declarative information. This clear distinction of gender is in line with the results of a previous study [41].
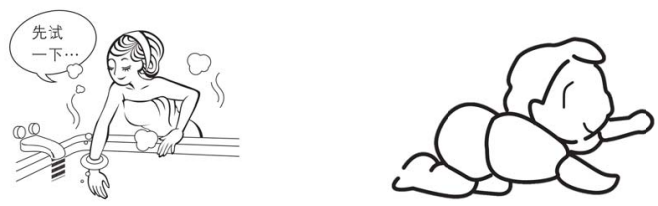

FigurE 3. EXAMPLE OF GENDER AND HUMAN APPEARANCE IN CHINESE MANUALS. 


\section{DISCUSSION}

This section discusses the key findings, the limitations, the implication for the industry as well as the academy, and possible future research directions.

\section{Conclusion}

Based on the literature, it is expected that there are more visuals in Chinese manuals [16], [17]. The results of this study are not completely in line with this expectation; there is no difference between the total number of visuals, but there are more visuals in declarative information in Chinese manuals than in Western manuals. Western manuals seem to contain more operational visuals.

Furthermore, some types of visuals are more often used in Chinese manuals. Previously published studies showed that there are more cartoons in high context cultures, such as Japan [20], [24], [25]. This study makes a further step to analyze Chinese culture and the results confirm that both cartoons and cartoons with personifications are more frequently present in Chinese manuals. Besides, as expected [2], [27], circuit diagrams showing professional knowledge to experts are found more often in Chinese manuals. On the other hand, some visual types appear more in Western manuals. The paper ascertains the notion that Chinese visuals show more detailed information of action steps [2]. In addition, a new finding is that technical line drawing pictures display more in Western manuals.

Another striking difference between these two cultures is how human beings are depicted; they are depicted in a detailed way in Chinese manuals while Western writers seem to avoid the appearance of human beings or the distinction between genders. This finding is newly raised in this study.

Besides, the data reported here appear to challenge the assumption that Chinese manuals are more colorful [37], as only the front page is proved more colorful in Chinese manuals rather than the whole manual.

Additionally, a significant difference shows that visuals in Chinese manuals are more often put right to text in declarative information, instead of vertically as was put forward by previous studies [16], [17].

It is an observable fact is that we did not find evidence of assumptions on neither the less clear relationship of visual and text [22], [27]-[29] nor the redundant or elaborative relationship [16] between Chinese and Western manuals.

The majority of differences mentioned above seem to imply that Western visuals tend to focus more on helping the user to finish tasks than Chinese manuals. So, there are more visuals in operational information, and visuals are specific, such as technical line drawings and detailed owing to detail-blow up pictures. On the other hand, the entertaining function seems to be more important in Chinese manuals; cartoons, friendly human images, and colorful front page contribute to creating a welcoming and comfortable environment for readers of Chinese manuals.

Of course, it should not be ignored that circuit diagrams are more often used in Chinese manuals, which might indicate that Chinese manuals also target at technicians such as maintenance persons, while Western manuals are only written for end users.

Summarizing, the study results indicate that the main difference between Chinese and Western manuals is the emphasis on the entertaining and the functional role of manuals.

\section{Limitations}

Although this is a large content analysis, including 100 manuals, only manuals of household appliances are included, so the results may be affected by the characteristics of the industry. Apart from that, the results only reflect the design differences, but do not show the users' preferences, so we don't know, for example, whether it is true that people from different cultural backgrounds perceive colors in different ways [32], [42].

\section{- Implication for research and theory}

Many further studies can be done. To begin with, an experiment based on the differences found in this study can help to test whether Chinese people favor the entertaining visuals over functional one, and vice versa. Besides, some design constrains such as different standards and writing system between Chinese and Western cultures can be the reason that manuals in these two cultures differ from each other. Thus, it would be better to interview technical writers about their ideas on rhetorical strategies and constrains that may influence their designs. As well, it is also interesting to conduct the same content analysis on another type of industries. The coding scheme developed in this study can be applied in other similar studies to help researchers analyze visuals in a more systematic way.

\section{Implication for practice}

From the perspective of manuals, this study presents the different visual design strategies between China and Western countries. This can help technical communicators realize the different strategies. Moreover, with this difference in mind, marketing personnel can understand the cultural difference better and may perform better in both markets. In the end, this difference reflects popular design in both cultures, so for practitioners in other fields, such as scientific communication, it also offers a valuable reference.

\section{ACKNOWLEDGEMENTS}

The research has received funding from the China Scholarship Council (File No. 201506010301). 


\section{REFERENCES}

[1] K. W. Houp, T. E. Pearsall, E. Tebeaux, and S. Dragga, Reporting Technical Information, 10th ed. New York (NY): Oxford University Press, 2002.

[2] Q. Wang, "A cross-cultural comparison of the use of graphics in scientific and technical communication," Tech. Commun., vol. 47, no. 4, pp. 553-560, 2000.

[3] C. Harrison, "Visual social semiotics: Understanding how still images make meaning," Tech. Commun., vol. 50, no. 1, pp. 46-60, 2003.

[4] Y. Zhang, "Illustrating beauty and utility: Visual rhetoric in two medical texts written in Chinas Northern Song dynasty, 960-1127," J. Tech. Writ. Commun., vol. 46, no. 2, pp. 172-205, 2016.

[5] K. St. Amant, "Introduction to the special issue: cultural considerations for communication design: Integrating ideas of culture, communication, and context into user experience design," Commun. Des. Q. Rev., vol. 4, no. 1, pp. 6-22, 2016.

[6] R. Willerton, "Visual metonymy and synecdoche: rhetoric for stage-setting images," J. Tech. Writ. Commun., vol. 35, no. 1, pp. 3-31, 2005.

[7] S. Dragga and D. Voss, "Cruel pies: The inhumanity of technical illustrations," Tech. Commun., vol. 48, no. 3, pp. 265 274, 2001.

[8] K. St. Amant, "A prototype theory approach to international image design," IEEE Trans. Prof. Commun., vol. 48, no. 2, pp. 219-222, 2005.

[9] K. St. Amant, "Of scripts and prototypes: A two-part approach to user experience design for international contexts," Tech. Commun., vol. 64, no. 2, pp. 113-125, 2017.

[10] J. H. Kim and K. Lee, "Culturally adapted mobile phone interface design: correlation between categorization style and menu structure," Proc. 9th Int. Conf. Hum. Comput. Interact. with Mob. devices Serv., pp. 379-382, 2007.

[11] D. Cyr, "Modeling web site design across cultures: Relationships to trust, satisfaction, and e-loyalty," J. Manag. Inf. Syst., vol. 24, no. 4, pp. 47-72, 2008.

[12] B. R. Moore, "Designing for multicultural and international audiences: Creating culturally-intelligent visual rhetoric and overcoming ethnocentrism," University of Central Florida, 2010 .

[13] R. E. Nisbett, K. Peng, I. Choi, and A. Norenzayan, "Culture and systems of thought: holistic versus analytic cognition.," Psychol. Rev., vol. 108, no. 2, pp. 291-310, 2001.

[14] E. T. Hall, Beyond Culture. New York (NY): Anchor Books, 1976.
[15] A. Auinger, A. Aistleithner, H. Kindermann, and A. Holzinger, "Conformity with user expectations on the web: Are there cultural differences for design principles?," in Design, User Experience, and Usability. Theory, Methods, Tools and Practice - First International Conference, Duxu 2011, 2011, pp. $3-12$.

[16] Y. Wang, Y. Jiang, and D. Wang, "Culture and text-graphic relationship-A study of automotive service literature from China and Germany," in Professional Communication Conference, 2007. IPCC 2007. IEEE International, 2007, pp. 1-8.

[17] Y. Wang and D. Wang, "Cultural contexts in technical communication: A study of Chinese and German automobile literature," Tech. Commun., vol. 56, no. 1, pp. 39-50, 2009.

[18] K. C. Kong, "A corpus-based study in comparing the multimodality of Chinese- and English- language newspapers," Vis. Commun., vol. 12, no. 2, pp. 173-196, 2013.

[19] H. C. L. Hsieh and S. D. Hong, "Localization of web design: An investigation of culturally preferred web attributes in Taiwan and the UK," in Cross-Cultural Design. Cultural Differences in Everyday Life. CCD 2013, 2013, pp. 404-413.

[20] T. Carroll and J. Delin, "Written instructions in Japanese and English: A comparative analysis," Pragmatics, vol. 8, no. 3, pp. 339-385, 1998.

[21] P. Honold, "Learning how to use a cellular phone: Comparison between German and Chinese users," Tech. Commun., vol. 46, no. 2, pp. 196-205, 1999.

[22] D. D. Ding, "Introducing China's first comprehensive technical writing book: On technological subjects by Song Yingxing," J. Tech. Writ. Commun., vol. 40, no. 2, pp. 161-177, 2010.

[23] P. Rubens, Science and Technical Writing: A Manual of Style. New York, NY: Routledge, 2001.

[24] R. G. Carpenter, "Designing for a Japanese high context culture: culture's influence on the technical writer's visual rhetoric," University of Central Florida, 2003.

[25] W. Fukuoka, Y. Kojima, and J. H. Spyridakis, "Illustrations in user manuals: Preference and effectiveness with Japanese and American readers," New York, vol. 46, no. January, pp. 167 176,1999

[26] S. Li, "Discuss of product experience design based on operation manual (in Chinese)," Design, no. 1, pp. 6-8, 2014.

[27] Q. Dong, "Cross-cultural considerations in instructional documentation: contrasting Chinese and U.S. home heater manuals," ACM 25th Int. Conf. Des. Commun., pp. 221-228, 2007.

[28] D. D. Ding, "The emergence of technical communication in China Yi Jing - (I Ching) the budding of a tradition," J. Bus. Tech. Commun., vol. 17, no. 3, pp. 319-345, 2003. 
[29] C. M. Barnum and H. Li, "Chinese and American technical communication: A cross-cultural comparison of differences," Tech. Commun., vol. 53, no. 2, pp. 143-166, 2006.

[30] K. A. Schriver, Dynamics in document design: creating text for readers. New York, NY: John Wiley \& Sons, Inc, 1997.

[31] R. N. Carney and J. R. Levin, "Pictorial illustrations still improve students' learning from text," Educ. Psychol. Rev., vol. 14 , no. 1, pp. 5-26, 2002.

[32] D. Wilcox, J. Thall, and A. Wilcox, "Visual literacy and instructional images for an increasingly global audience."

[33] K. Maitra and D. Goswami, "Responses of American readers to visual aspects of a mid-sized Japanese company's annual report: a case study," IEEE Trans. Prof. Commun., vol. 38, no. 4, pp. 197-203, 1995.

[34] K. W. Houp, T. E. Pearsall, E. Tebeaux, and S. Dragga, Reporting Technical Information. Boston: Allyn and Bacon: Oxford University Press, 2002.

[35] T.-F. Kummer, J. Recker, and J. Mendling, "Enhancing understandability of process models through cultural-dependent color adjustments," Decis. Support Syst., 2016.

[36] K. Reinecke and A. Bernstein, "Improving performance, perceived usability, and aesthetics with culturally adaptive user interfaces," ACM Trans. Comput. Interact., vol. 18, no. 2, pp. 129,2011

[37] E. Würtz, "Intercultural communication on web sites: a cross-cultural analysis of web sites from high-context cultures and low-context cultures," J. Comput. Commun., vol. 11, no. 1, pp. 274-299, 2005.

[38] T. Tenbrink and A. Maas, "Efficiently connecting textual and visual information in operating instructions," IEEE Trans. Prof. Commun., vol. 58, no. 4, pp. 346-366, 2015.

[39] N. S. Germaine-Madison, "Instructions, visuals, and the English-speaking bias in technical communication," Tech. Commun., vol. 53, no. 2, pp. 184-194, 2006.

[40] X. Li, "From globalization to glocalization--what the impacts of globalization on Chinese document design tell us about international professional communication," Clemson University, 2011.

[41] M. Hall, M. De Jong, and M. Steehouder, "Cultural differences and usability evaluation: Individualistic and collectivistic participants compared," Tech. Commun., vol. 51, no. 4, pp. 489-503, 2004.

[42] L. Liu, U. M. Hölscher, and Z. Yao, "Cultural diversity New challenge to medical device use safety for international markets," in Cross-Cultural Design. Cultural Differences in Everyday Life. CCD 2013., 2013, pp. 127-136.

\section{ABOUT THE AUTHORS}

Qian Li is a PhD student at the University of Twente, Enschede (The Netherlands). Her research interests concern the cultural differences in technical communication.

Joyce Karreman is an assistant professor of Technical Communication at the University of Twente, the Netherlands. She received her $\mathrm{PhD}$ in technical communication from this university. Her research interests include the design of instructive documents, user-centered design, and intercultural issues related to usability and user experience. She has presented her work at international conferences on technical and professional communication and has published in several journals.

Menno D.T. de Jong is a full professor of Communication Science at the University of Twente (The Netherlands). His main research interests include technical communication (usability, user experience, and the appropriation of technology) and organizational communication. 